\title{
Variation of prostate-specific antigen expression in different tumour growth patterns present in prostatectomy specimens
}

\author{
M. P. W. Gallee ${ }^{1}$, E. Visser-de Jong ${ }^{1}$, J. A. G. M. van der Korput ${ }^{1}$, Th. H. van der Kwast ${ }^{1}$, F. J. W. ten Kate ${ }^{1}$, \\ F. H. Schroeder ${ }^{2}$, and J. Trapman ${ }^{1}$ \\ Departments of ${ }^{1}$ Pathology and ${ }^{2}$ Urology, Erasmus University, Rotterdam, The Netherlands \\ Accepted: July 1, 1989
}

Summary. A series of 55 randomly chosen radical prostatectomy specimens was analyzed for expression of prostate-specific antigen (PSA) by immunohistochemical techniques. Tissue sections were selected in such a manner that in addition to glandular benign prostatic hyperplasia (BPH), one or more different prostatic tumour growth patterns were present. Four monoclonal antibodies, directed against three different PSA epitopes, and one polyclonal anti-PSA antiserum were used. Expression of PSA was compared with that of prostate-specific acid phosphatase (PAP), recognized by two different polyclonal antisera. A critical dilution aimed at a maximum of staining intensity on BPH tissue sections was chosen for all antibodies. Anti-PSA and anti-PAP antisera stained essentially all BPH samples (over $90 \%$ ). Irrespective of the nature of the antibodies used, PSA expression was found to be decreased in prostatic carcinoma. A clear cut relationship was found between immunoreactivity for PSA and the degree of differentiation of the tumour area. Under the experimental conditions used the PSA monoclonal antibodies stained only 1 out of 10 undifferentiated carcinomas, whereas $50 \%$ to $70 \%$ of the well- and moderately-differentiated carcinomas showed immunoreactivity. This correlation was less pronounced with the PAP staining pattern. If the PSA antibody titer was raised the percentage of clearly staining undifferentiated carcinomas could be considerably increased (up to $60 \%$ $100 \%$ ), indicating that PSA expression is not absent, but lowered in most (if not all) undifferentiated carcinomas.

Key words: Prostatic carcinoma - Prostate-specific antigen - Prostate-specific acid phosphatase - Immunohistochemistry - Differential expression - Tumour architecture

Prostate-specific antigen (PSA) was first described by Wang and co-workers $[21,28,29]$. It belongs to a family of kallikrein-like serine proteases and has a molecular weight of 33-35 $\mathrm{kD}[3,30]$. Recently, the primary structure of the PSA protein obtained by direct sequencing or deduced from the cDNA sequence has been elucidated $[18,24,30]$. PSA is exclusively secreted by the epithelial cells of the prostatic gland. Because of its tissue-specific expression pattern, PSA became of interest as being a prostatespecific (tumour) marker. Availability of specific polyclonal and monoclonal antibodies also made its immunohistochemical detection in neoplastic and non-neoplastic prostatic tissue possible $[6,11,12,22]$. In addition, it turned out that the presence of PSA in sera of patients could be used for monitoring the natural course of prostatic cancer and to evaluate the success or failure of therapeutic (often endocrine) regimens [27].

Especially because of the general acceptance of PSA as being the most reliable and sensitive prostate (tumour) marker in serological assays, detailed analysis of PSA expression in prostatic tumours is of high importance. Several studies have been presented aiming to gain a better insight into the specificity and sensitivity of PSA expression in prostatic tumours $[1,2,5,7,8-10,16,23,26]$. To extend our knowledge further in this regard we investigated PSA expression in tissue sections derived from radical prostatectomy preparations. Prostatectomy was performed for localized prostatic carcinoma. Prostatic carcinomas are often composed of different growth patterns within a single tumour. This provided an ideal opportunity to compare in detail the immunohistochemical levels of PSA with prostatic tumour differentiation status. Since no consensus has been reached concerning the most suited histological grading system for prostatic cancer, immunohistochemical results were not correlated with grading scores. In addition to PSA expression we also studied prostate-specific acid phoshatase (PAP) expression in this material.

\section{Materials and methods}

\section{Prostatic tissue}

Prostatic tissues used in this study were obtained from prostatectomy specimens. Fifty-five patients (randomly selected from a much 
Table 1. Distribution of different histological patterns of prostatic carcinoma and benign prostatic hyperplasia in prostatectomy specimens obtained from 55 patients with localized carcinoma

Well differentiated adenocarcinoma (WDA)

Moderately differentiated adenocarcinoma (MDA)

Poorly differentiated adenocarcinoma (PDA)

Undifferentiated carcinoma (UC)

Clear cell carcinoma $(\mathrm{CCC})$

Solid tumour areas (STA)

Cribriform carcinoma (CC)

Benign prostatic hyperplasia (BPH)

\section{6}

10

12

8

19

55

larger series) with clinically staged localized prostatic carcinoma (T1, T2 and T3) were treated by radical prostatectomy in the years 1980-1987 at the Department of Urology of Erasmus University Rotterdam. Patients did not receive any therapy prior to surgery.

All immunohistochemical assays were performed on surgical prostatectomy specimens. These specimens were routinely fixed in $10 \%$ buffered formalin, sectioned perpendicular to the prostatic urethra and submitted completely for histological examination. Tissues were routinely handled and stained with haematoxilinazofloxin. The number of sections per specimen varied from 24 to 43 . Of each specimen two slides were selected in which equally distributed glandular benign prostatic hyperplasia (BPH) and tumour areas were present. In all slides different subtypes of prostatic carcinoma based predominantly upon histological features could be distinguished. Apart from well-, moderately-, and poorlydifferentiated adenocarcinomas, a cribriform growth pattern, and an undifferentiated (diffusely infiltrating variant without acinar formations) subtype were present in our material. In addition, a growth variant characterized by solid undifferentiated tumour areas (medullary growth pattern) and the so-called hypernephroid or clear cell type (showing resemblance with adenocarcinoma renis) were discerned (see Table 1). Tumour patterns with typical endometrioid features were not present in our material.

\section{Primary antibodies}

PSA specific antibodies. PSA purified from extracts of BPH tissue by affinity choromatography using the PSA-specific monoclonal antibody ER-Pr1 (12) was applied to generate mouse monoclonal antibodies and a rabbit polyclonal antiserum (PSA(pc)) using standard procedures. Details will be published elsewhere. In short, specificity of the antibodies was checked by immuno-(Western-) blotting and immunohistochemistry using extracts and tissue sections of malignant and non-malignant human tissues from different origins. Three monoclonal antibodies (ER-Pr8, 12 and 27) which showed the highest reactivity with formalin-fixed paraffin-embedded prostate tissue were analyzed in detail. All antibodies were reactive with a $33-35 \mathrm{kD}$ protein, recognized as PSA. Monoclonal antibodies were of the IgG1 subclass. Ascites batches with high concentrations of monoclonal antibodies were used for further studies. The four monoclonal antibodies defined three unique antigenic determinants of PSA as established by competition ELISA assays. ER-Pr8 and ER-Pr27 were directed against the same PSAepitope. Antibodies were titrated for optimalization of the most suitable dilution for immunohistochemistry. Dilutions of all antibodies were selected in such a manner that further lowering of the concentration resulted in a decrease of staining intensity of $\mathrm{BPH}$ control sections.

$P A P$ specific antibodies. A commercially available rabbit polyclonal antibody directed against PAP was obtained from Cambridge
Research Laboratory, Cambridge, Massachusetts (Com-PAP(pc)). Additionally, a rabbit polyclonal antiserum (PAP(pc)) was prepared in our own laboratory. PAP was purified from $\mathrm{BPH}$ tissue by affinity chromatography using a PAP-specific $\mathrm{McAb}$, which was able to bind PAP but did not recognize PAP in formalin-fixed tissue. Specificity of this polyclonal antiserum was assessed by means of the Western blot technique and immunohistochemistry. As cross-reactivity existed at immunohistochemical level, the rabbit anti-PAP serum was extensively adsorbed with acetone-dried human pancreatic and kidney tissue powder. The resulting purified antiserum (PAP(pc)) showed no reactivity with pancreatic island cells, kidney tubules, mast cells or granulocytes.

As described above for the PSA antibodies, PAP antibodies were used in such a dilution that further lowering of the concentration resulted in a decrease of staining intensity of BPH control tissue.

Immunohistochemistry. Consecutive paraffin sections were cut at 5 $\mu \mathrm{m}$ thickness. After rehydration of the deparaffinized sections, the sections were treated for $20 \mathrm{~min}$ with absolute methyl alcohol, containing $0.3 \% \mathrm{H}_{2} \mathrm{O}_{2}$ to block endogenous peroxidase activity. Subsequently, sections were rinsed in PBS. Primary antibodies were applied for $1 \mathrm{~h}$ at $37^{\circ} \mathrm{C}$. Subsequently, slides were incubated with peroxidase conjugated antisera (P-rabbit anti-mouse or P-conjugated swine anti-rabbit; Dakopatts Denmark) for $1 \mathrm{hr}$ at room temperature. Peroxidase activity was visualized by incubating the sections in Tris-HC1 buffer $(0.05 \mathrm{M}, \mathrm{pH} 7.4)$ containing $0.0125 \%$ 3,3'-diamino benzidine tetrahydrochloride (Fluka AG, Switserland) activated by $0.03 \% \mathrm{H}_{2} \mathrm{O}_{2}(10 \mathrm{~min}$ at room temperature). In all cases a brief nuclear counter stain with Mayer's haematoxilin was performed.

Finally, sections were dehydrated, mounted in malinol and examined microscopically. Appropriate positive (BPH) and negative control slides were processed in an identical manner. Intraepithelial staining intensities were judged subjectively as 0 (absent), 1 (faint), 2 (moderate), or 3 (strong). For purpose of presentation 0 and 1 were considered as negative, 2 and 3 as positive results. Since heterogeneity (variation in number of tumour cells that stain positively) even within the same histological subtype was often present, only areas with the highest staining intensity were judged in both BPH and prostatic carcinoma.

\section{Results}

\section{Histology of prostatectomy specimens}

It is well established that prostate tumours are very heterogeneous. In the prostatectomy specimens investigated in this study, adjacent to prostatic carcinoma, areas of proliferative benign epithelial glandular structures (glandular-BPH) were present in all sections. In some areas groups of hyperplastic glands were arranged in nodular formations. In the 55 cases examined, tumour heterogeneity was reflected by the large number of different growth patterns present in each sample. Although the subdivision of growth characteristics of prostatic carcinoma such as represented in Table 1 is somewhat arbitrary, in our set of tumours the whole range of histological subtypes in nearly every combination was detectable and varied from only 1 histological carcinoma type in 4 cases to 5 different patterns in 3 specimens. Adenocarcinomas with gland formation, irrespective their degree of differentiation, were most frequently observed. Tumours consisting of glandular structures were subdivided into well-, moderately- and poorlydifferentiated carcinomas based upon diameter of tumour 
Table 2. Number of prostatectomy specimens (\%) with indicated staining for PSA (scored 2 or 3)/total no specimens in benign prostatic hyperplasia $(\mathrm{BPH})$ and prostatic carcinoma regardless its histological growth characteristics

\begin{tabular}{lll}
\hline Antibodies & BPH & Carcinoma \\
\hline PSA(pc) & $53 / 55(96 \%)$ & $41 / 55(75 \%)$ \\
ER-Pr1 & $48 / 55(87 \%)$ & $35 / 55(64 \%)$ \\
ER-Pr8 & $50 / 55(91 \%)$ & $40 / 55(73 \%)$ \\
ER-Pr12 & $52 / 55(95 \%)$ & $36 / 55(65 \%)$ \\
ER-Pr27 & $54 / 55(98 \%)$ & $41 / 55(75 \%)$ \\
\hline
\end{tabular}

glands and their resemblance to normal prostatic glandular structures. A cribriform growth pattern was considered as a seperate entity. A total lack of glandular formations in tumour tissue was only found in 5 specimens.

\section{Expression of PSA in various prostate tumour growth patterns and BPH present in prostatectomy specimens}

The set of 55 prostatectomy preparations was analyzed for expression of PSA by immunohistochemical techniques using four different monoclonal antibodies directed against three different epitopes and a polyclonal antiserum (PSA(pc)) (see Materials and methods). In BPH tissue sections some heterogeneity in immunostaining patterns was observed with all antibody preparations used. This heterogeneity was most prominent when monoclonal antibody ER-Pr1 was applied. Heterogeneity was rarely detected in epithelial cells lining the same gland, but was observed as a variation of staining of different glands. The heterogeneity observed with monoclonal antibody ER-Pr 1 could partially be due to a less stable appearance of the PSA antigenic site recognized by this antibody. In spite of the presence of some unstained glands, essentially all (91\%-98\%) BPH specimens examined were clearly stained with three out of four monoclonal antibodies and the polyclonal antiserum against PSA. ER-Prl gave somewhat lower figures (Table 2 and Fig. 1).

We examined PSA expression in prostatic carcinoma in the same tissue slides as used for the study of PSA in $\mathrm{BPH}$. Without subdividing the tumour regions into different growth patterns, the immunostaining for PSA was scored between $64 \%$ and $75 \%$ of the sections examined (Table 2). Similarly as noted in BPH tissue sections, ER-Pr1 stained the smallest number of slides (35 out of 55), whereas the polyclonal antiserum (PSA(pc)) and the monoclonal antibody ER-Pr27 showed the highest percentage of positives (75\%). Figure 2 depicts four examples of lowered or even absent PSA staining in carcinoma areas as compared to the internal BPH control. If PSA expression was compared for the various tumour growth patterns as summariazed in Table 1 an interesting distribution could be observed (Fig. 1). Fifty to $70 \%$ of those tumour areas that consisted of glandular structures and designated as well- or moderately-differentiated adenocarcinomas stained positively for PSA. The variation of

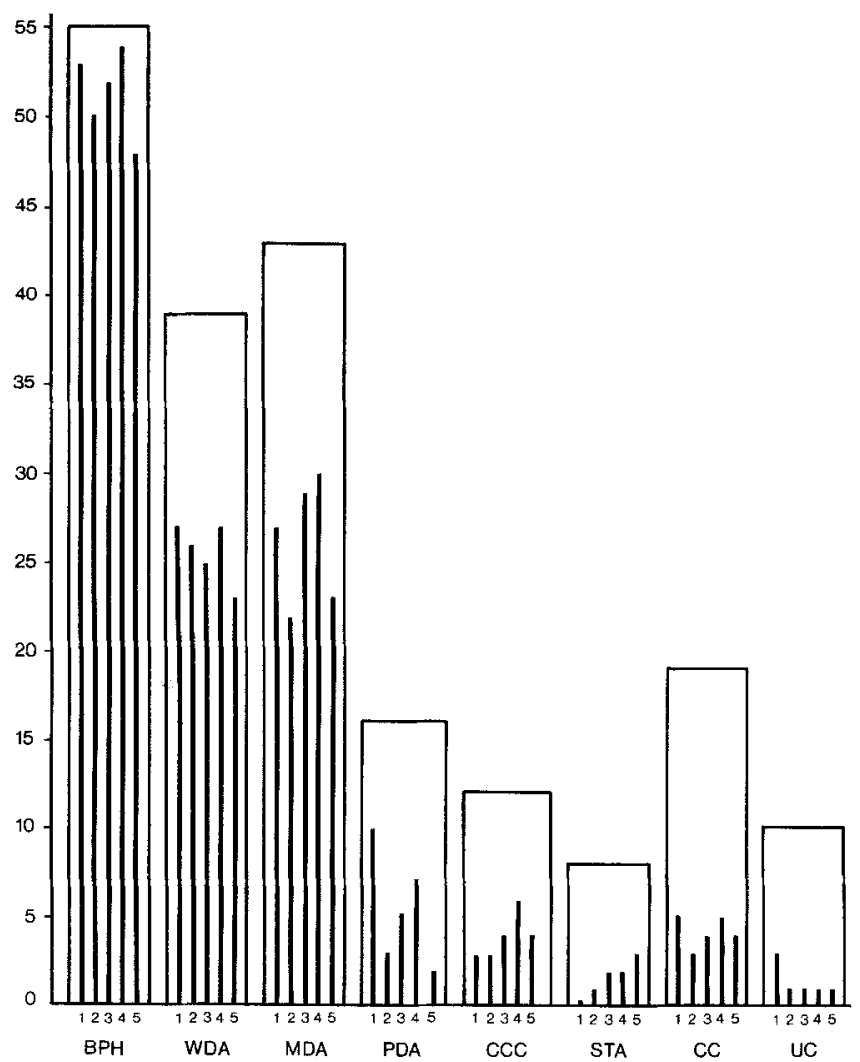

Fig. 1. Schematic presentation of PSA-immunoractivity (scored 2 and 3) in $\mathrm{BPH}$ areas and various growth patterns of prostatic carcinoma, determined by polyclonal (PSA(pc)) - and McAbs (ERPr1, 8, 12, and 27). 1: PSA(pc); 2: ER-Pr8; 3: ER-Pr12; 4: ER-Pr27; 5: ER-Pr1. Abbreviations of growth patterns are as described in Table 1. Number of staining tissue sections $=\mathrm{I}$; total number of tissue sections $\square$

staining scored in our series of poorly-differentiated adenocarcinoma is possibly due to some difficulties in determining the histological criteria for this subgroup. The same is true for the small group of solid undifferentiated tumours (Fig. 1). In general, however, this growth pattern showed a low percentage of positives. The cribriform growing tumour areas also showed a low staining percentage ( 26 or less).

The difference between PSA expression in tumour tissue and BPH tissue was most striking in the sections containing undifferentiated carcinoma. In the latter group almost none of the tumour areas could be stained. As stated in the method section we used PSA antibodies at such a concentration that further dilution would cause a decrease in the staining intensity of BPH controls. Therefore, the results obtained reflect the maximal difference in PSA expression detectable with immunohistochemical techniques in the various tumour growth patterns and BPH.

To investigate the effect of antibody concentration on detection of PSA expression the 10 slides containing undifferentiated carcinoma areas were re-examined with a ten-fold higher PSA antibody concentration. Results are summarized in Table 3. All antibodies used showed essentially the same shift in staining intensity. At the low 

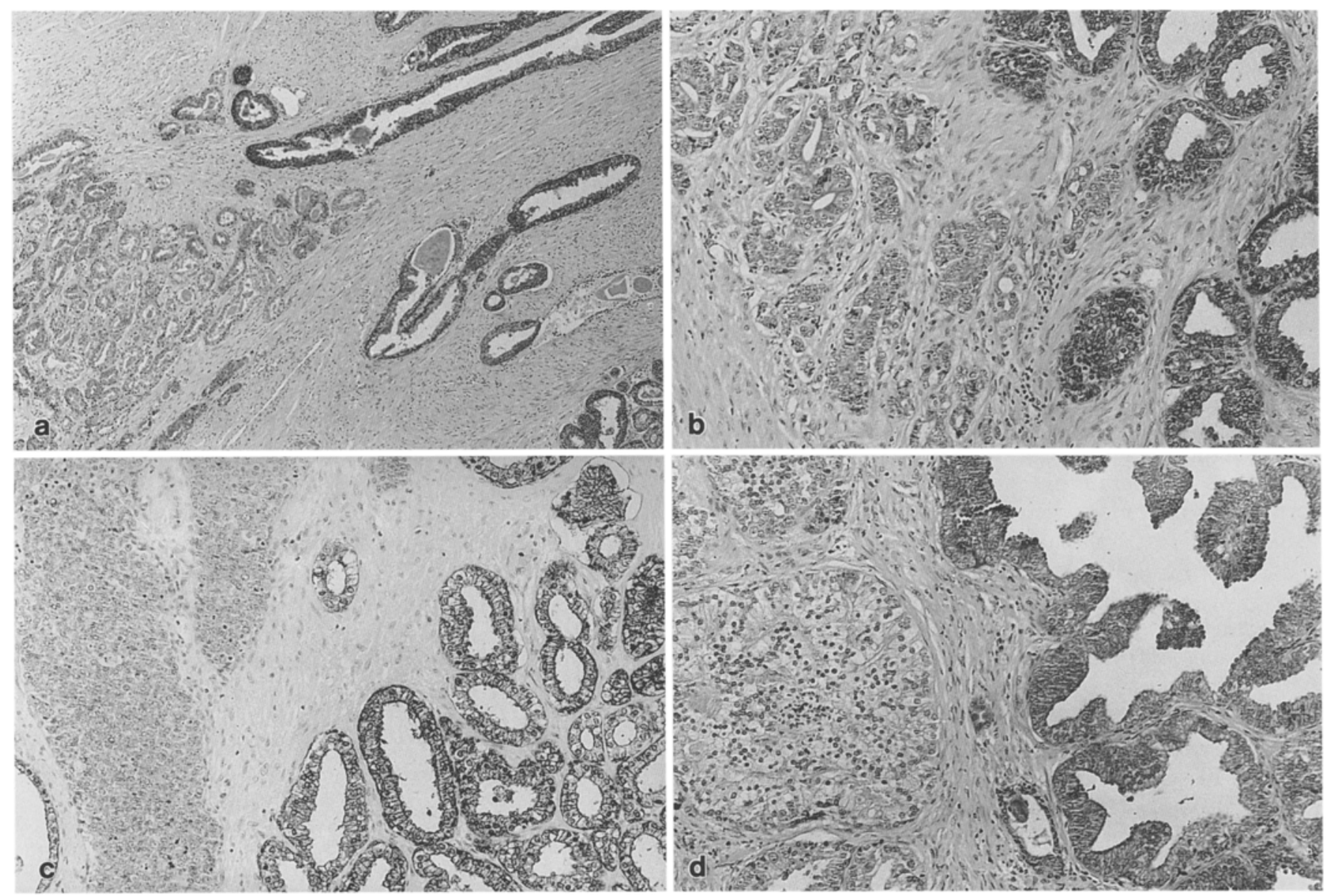

Fig. 2a-d. Examples of diminished or absent (scored 1 or 0 ) PSAimmunoreactivity in growth patterns of prostatic carcinoma. At the right side of every photograph an area of BPH is present. Original magnification $150 \times$. Selected antibody titers were based on maximum staining in BPH areas. a moderately differentiated adenocarcinoma; section stained by the antibody ER-Pr27. b moderately differentiated adenocarcinoma; section stained by the antibody ERPr27. c Solid tumour areas; section stained by the antibody ER-Pr12. d cribriform carcinoma; section stained by the antibody ER-Pr27

antibody titer staining could only be detected in a small number of the undifferentiated carcinomas, whereas application of high antibody titers resulted in staining of the majority of the undifferentiated prostate tumours. It is obvious from these results that differences in PSA expression level can only be clearly detected if carefully controlled experimental conditions are applied.

\section{Comparison of PSA and PAP expression in prostatic tumour sections}

Two different polyclonal antisera against PAP (Com$\mathrm{PAP}(\mathrm{pc})$ and $\mathrm{PAP}(\mathrm{pc})$; see Materials and methods section) were used for comparison of PAP expression with that of PSA in various prostate tumour growth patterns. Similarly as described for PSA antibodies, PAP antibodies were applied at such a concentration that further dilution would result in decreased staining of BPH tissue sections. Figure 3 shows an example of the immunostaining found with a PSA and a PAP antibody. In this particular tumour area PSA was absent using the initial antibody titer, whereas PAP could be readily demonstrated. Further results are presented in Fig. 4. Identical to PSA, PAP expression assessed by either antiserum was found to be lower in tumour areas as compared to BPH. However, the

Table 3. Distribution of immunostaining intensity scores (scores 0 and 1 are combined) of PSA within undifferentiated carcinoma areas assessed by polyclonal (PSA(pc)) and monoclonal antibodies (ER-Pr12; ER-Pr8) using two different concentrations of the primary antibody

\begin{tabular}{lllllllll}
\hline & 0,1 & 2 & 3 & & & 0,1 & 2 \\
\hline PSA(pc) & $1: 6400$ & 7 & 3 & 0 & PSA(pc) & $1: 640$ & & 0 \\
ER-Pr12 & $1: 102.400$ & 9 & 1 & 0 & ER-Pr12 & $1: 10.240$ & 8 & 2 \\
ER-Pr8 & $1: 51.200$ & 9 & 1 & 0 & ER-Pr8 & $1: 5.120$ & 4 & 3 \\
\hline
\end{tabular}




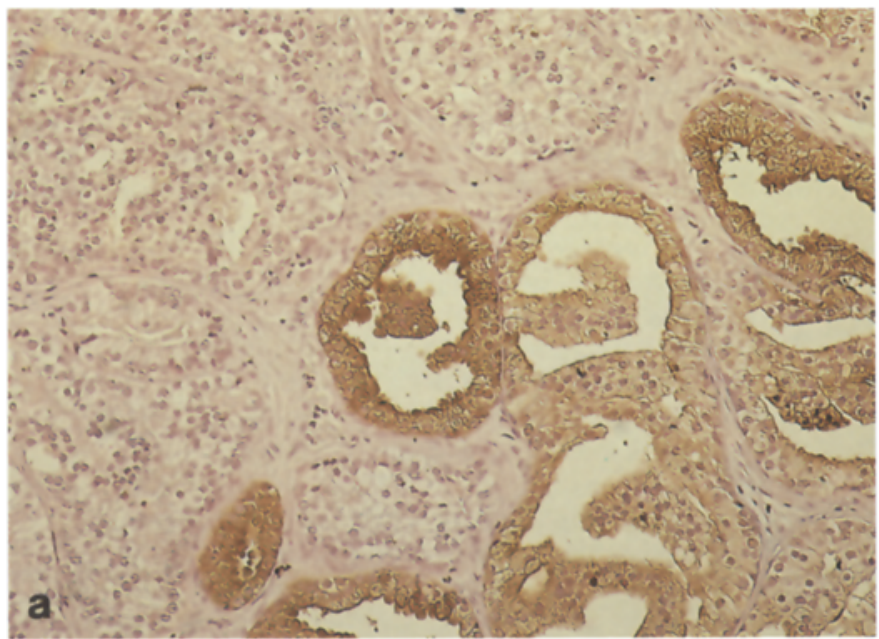

Fig. 3a and b. Prostatectomy tissue section showing BPH and an area of moderately differentiated adenocarcinoma. Consecutive slides were stained by the anti-PSA antibody ER-Pr12 a and the PAP(pc) antiserum $\mathbf{b}$. Chosen antibody titers were based on maximum staining in BPH areas. In the tumor area PSA could not be demonstrated, whereas PAP could be detected more readily. Original magnification $150 \times$

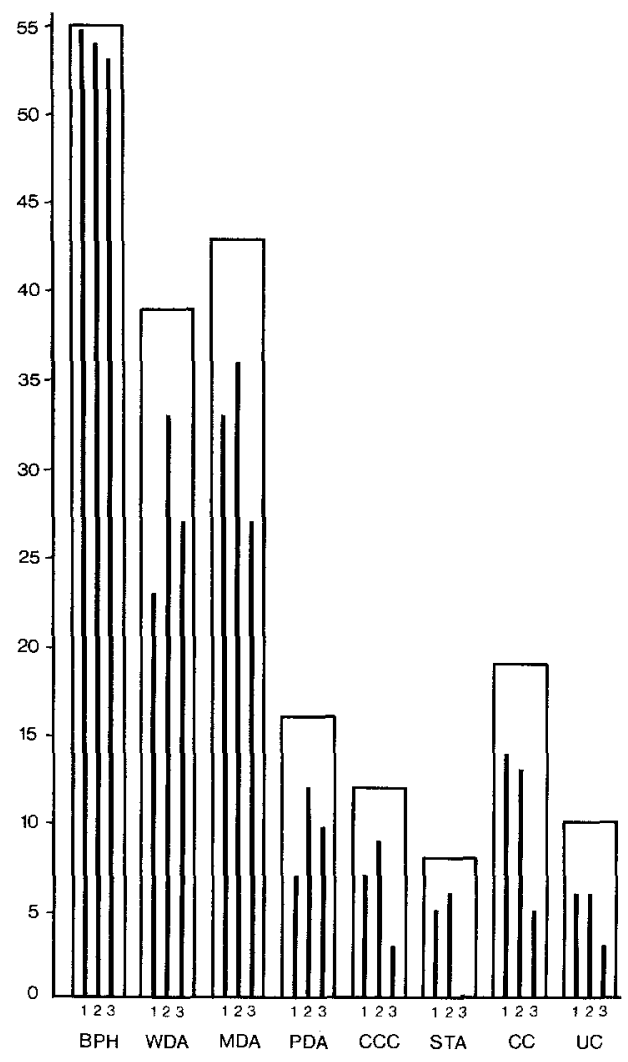

Fig. 4. Schematic presentation of PSA- and PAP immunoreactivity (scored 2 and 3) in BPH areas and various growth patterns of prostatic carcinoma, determined by polyclonal antibodies Com$\operatorname{PAP}(\mathrm{pc})(1), \mathrm{PAP}(\mathrm{pc})(2)$ and PSA(pc) (3). Abbreviations of growth patterns are as described in Table 1 . Number of staining tissue sections $=\mathrm{I}$; total number of tissue sections $=\square$

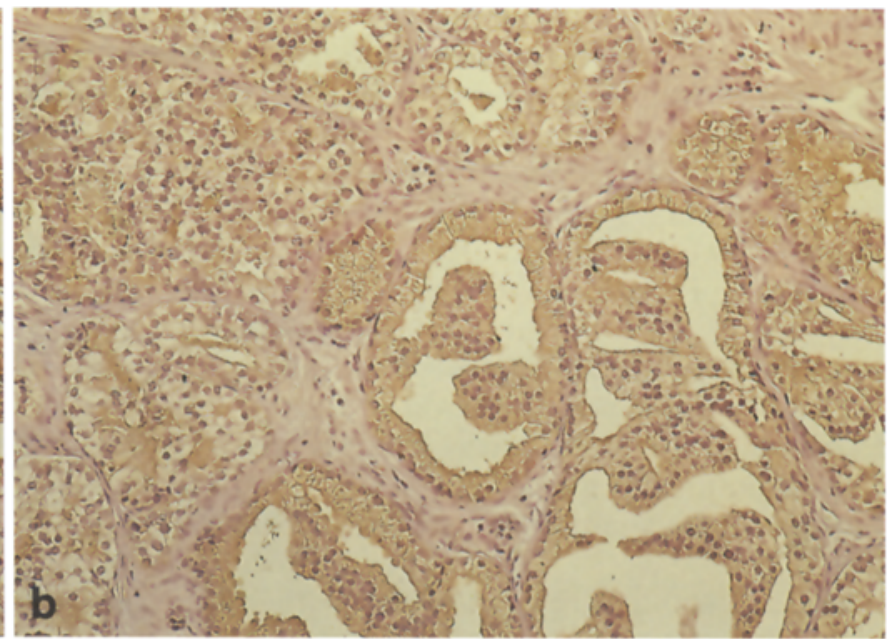

differences observed were much less pronounced. Comparison of PSA and PAP expression in undifferentiated carcinoma and in cribriform carcinoma shows that the majority of sections examined were positively stained with PAP antibodies, whereas the PSA antibodies were in general negative (Figs. 1 and 4 ). Both antisera against PAP gave essentially identical results. From these data we concluded that, in contrast to PSA, PAP expression is considerably less correlated with tumor-differentiation.

\section{Discussion}

Although now accepted as a reliable marker for prostatic carcinoma both in serological and immunohistochemical assays the detailed possibilities of application of PSA expression as a tool for characterization of neoplastic cells of prostatic origin and its precise correlation with tumour differentiation are still a matter of dispute. This especially concerns fluctuation in PSA expression in various tumours and the sensitivity of PSA as compared to PAP. In this study PSA expression was investigated in various growth patterns of prostatic carcinoma present in prostatectomy specimens. Prostatectomy was performed without prior therapy. In general, several different growth patterns could be distinguished in each prostatectomy specimen and were often even present in one single tissue slide. As an internal control all tissue sections examined contained, in addition to tumour regions, areas of $\mathrm{BPH}$. By this approach fluctuations in the data due to experimental artefacts or differences in the quality of the tissue slides could be reduced to a minimum. PSA expression was correlated to the differentiation status of a tumour area. Since consensus is lacking referring the most appropriate grading method for prostatic carcinoma no attempts were made to compare immunohistochemical findings with scores of one of the various grading systems described $[13,15,19,20]$.

The data obtained clearly show a difference in PSA expression in BPH and prostatic carcinoma irrespective of its histological features. Most pronounced differences were detected between undifferentiated tumours and the BPH control. Under well-defined conditions (low anti- 
body concentration) the majority of undifferentiated tumour areas were negative when stained with five different PSA antibodies. In most studies described so far, a much higher percentage of PSA positive tumours has been reported $[1,7,8,10,23]$, although in part of these less intense staining of less-differentiated tumours has been noticed. Two of the more recent studies mention the absence of PSA staining in (part of) undifferentiated tumours $[9,16]$. Further experiments presented here clearly establish that choice of the antibody titer for immunohistochemical detection of PSA in tumour material is of utmost importance. If higher concentrations of specific antibodies are used most of the undifferentiated tumour sections in prostatectomy specimens stain positively.

These data confirm and extend earlier observations that PSA is a very good marker for prostate carcinoma. Furthermore, the data presented here indicate that at least those monoclonal antibodies which are directed against dominant epitopes of PSA (in this study ER-Pr8 and ERPr27) are very useful in diagnostic pathology and do not differ in sensitivity from polyclonal antibodies. Our results may lend support to the assumption that a decrease of PSA concentration in the sera of patients with prostatic carcinoma not always has to reflect a successful therapeutic intervention, but may also be the result of dominant progressive growth of undifferentiated prostatic carcinoma. More extensive studies correlating immunohistochemical data with PSA serum levels have to be initiated to gain better insight in this phenomenon. Moreover, it is our opinion that during monitoring of endocrine therapy special care must be taken in the accurate interpretation of a decrease of serum PSA concentration, especially since there are indications that PSA expression is influenced by hormones [14].

In contrast to the results obtained on PSA a definite relationship between histopathological growth patterns and PAP expression was less apparent. Even at the experimental conditions chosen which were optimal for the visualization of differential expression, the differences in PAP expression level in the various tumour sections were small. From our data it can only be concluded that in tumour regions PAP expression is slightly reduced. Our data support those earlier observations showing that in undifferentiated prostatic tumours the presence of PAPcan be more easily detected than PSA $[4,5,9,14,16,17]$. However, our findings contradict the reports of others in which no difference or even a better PSA staining was described in poorly- or undifferentiated prostatic carcinomas $[1,2,7,8,31]$. Since the prostate specificity of PAP antibodies is sometimes questioned [25], we find it to be important to use both PAP and PSA as prostatic tumour markers. PAP expression might provide more information on the prostate origin of a tumour, whereas PSA expression (or its absence) seems to be better correlated with histological differentiation.

Acknowledgements. The authors wish to thank Miss M. Hanegraaff for preparation of the manuscript and Miss P. Delfos for skillful photographic assistance.

\section{References}

1. Abrahamsson PA, Lilja H, Falkmer S, Wadstroem LB (1988) Immunohistochemical distribution of the three predominant secretory proteins in the parenchyma of hyperplastic and neoplastic prostate glands. Prostate 12:39

2. Allhoff EP, Proppe KH, Chapman CM, Lin CW, Prout GR (1983) Evaluation of prostate specific acid phosphatase and prostate-specific antigen in identification of prostatic cancer. $\mathrm{J}$ Urol 129:315

3. Ban Y, Wang MC, Watt KWK, Loor R, Chu TM (1984) The proteolytic activity of human prostate-specific antigen. Biochem Biophysic Res Commun 123:482

4. Bentz MS, Cohen C, Demers LM, Budgeon LR (1982) Immunohistochemical acid phosphatase level and tumor grade in prostatic carcinoma. Arch Pathol Lab Med 106:476

5. Bentz MS, Cohen C, Budgeon LR, Demers LM (1984) Evaluation of commercial immunoperoxidase kits in diagnosis of prostate carcinoma. Urology 23:75

6. Chu TM, Kawinski E, Hibi N, Croghan G, Wiley J, Killian CS, Corral D (1989) Prostate-specific antigenic domain of human prostate-specific antigen identified with monoclonal antibodies, J Urol 141:152

7. Ellis DW, leffers S, Davies JS, NgABP (1984) Multiple immunoperoxidase markers in benign hyperplasia and adenocarcinoma of the prostate. Am J Clin Pathol 81:279

8. Epstein JI, Eggleston JC (1984) Immunohistochemical localization of prostate specific acid phosphatase and prostate-specific antigen in stage A2 adenocarcinoma of the prostate: prognostic implications. Hum Pathol 15.853

9. Feiner HD, Gonzalez R (1986) Carcinoma of the prostate with atypical immunohistological features. Am J Surg Pathol 10:765

10. Ford TF, Butcher DN, Masters JRW, Parkingson MC (1985) Immunocytochemical localization of prostate-specific antigen: specificity and application to clinical practice. Br J Urol 57:50

11. Frankel AE, Rouse RV, Wang MC, Chu TM, Herzenberg LA (1982) Monoclonal antibodies to a human prostate antigen. Cancer Res 42:3714

12. Gallee MPW, Van Vroonhoven CCJ, Van der Korput JAGM, Van der Kwast ThH, Ten Kate FJW, Romijn JC, Trapman J (1986) Characterization of monoclonal antibodies raised against the prostatic cancer cell line PC-82. Prostate 9:33

13. Gleason DF (1966) Classification of prostatic carcinomas. Cancer Chemother Rep 50:125

14. Grignon D, Troster M (1985) Changes in immunohistochemical staining in prostatic adenocarcinoma following diethylstilbestrol therapy. Prostate 7:195

15. Kate ten FJW, Gallee MPW, Schmitz PIM, Joebsis AC, Van der Heul RO, Prins MEF, Blom JHM (1986) Problems in grading of prostatic carcinoma: interobserver reproducibility of five different grading systems. World J Urol 4:147

16. Keillor JS, Aterman K (1987) The response of poorly differentiated prostatic tumors to staining for prostate-specific antigen and prostatic acid phosphatase: a comparative study. J Urol 137:894

17. Lippert MC, Bensimon H, Javadpour N (1982) Immunoperoxidase staining of acid phosphatase ih human prostatic tissue. $J$ Urol 128:1114

18. Lundwall A, Lilja $H$ (1987) Molecular cloning of human prostate-specific antigen cDNA. FEBS Lett 214:317

19. Mostofi FK (1975) Grading of prostatic carcinoma. Cancer Chemother Rep 59:111

20. Murphy GP, Whitmore WF (1979) A report of the workshops on the current status of the histologic grading of prostate cancer. Cancer 44:1490

21. Papsidero LD, Kuriyama M, Wang MC, Horoszewicz J, Leong SS, Valenzuela L, Murphy GP, Chu MT (1981) Prostate antigen: a marker for human prostate epithelial cells. J Natl Cancer Inst $66: 37$ 
22. Papsidero LD, Croghan GA, Wang MC, Kuriyama M, Johnson EA, Valenzuela LA, Chu MT (1983) Monoclonal antibody (F5) to human prostate antigen. Hybridoma 2:139

23. Purnell DM, Heatfield BM, Trump BF (1984) Immunohistochemical evaluation of human prostatic carcinomas for carcinoembryonic antigen, nonspecific cross reacting antigen, beta chorionic gonadothrophin, and prostate-specific antigen. Cancer Res 44: 285

24. Riegman PHJ, Klaassen P, Van der Korput JAGM, Romijn JC, Trapman J (1988) Molecular cloning and characterization of novel prostate antigen cDNAs. Biochem Biophys Res Commun 155:181

25. Shaw LM, Yang N, Brooks JJ, Neat M, Marsh E, Seamonds B (1981) Immunochemical evaluation of the organ specificity of prostatic acid phosphatase. Clin Chem 27:1505

26. Sinha AA, Hagen KA, Sibley RK, Wilson MJ, Limas C, Reddy PK, Blackard CE, Gleason DF (1986) Analysis of fixation effects on immunohistochemical localization of prostatic specific antigen in human prostate. J Urol 136:722

27. Stamey TA, Yang N, Hay AR, McNeal JE, Preiha FS, Redwine E (1987) Prostate-specific antigen as a serum marker for adenocarcinoma of the prostate. N Engl J Med 317:909
28. Wang MC, Valenzuela LA, Murphy GP, Chu TM (1979) Purification of a human prostate-specific antigen. Invest Urol 17:159

29. Wang MC, Papsidero LD, Kuriyama M, Valenzuela LA, Murphy GP, Chu TM (1981) Prostate antigen: a new potential marker for prostatic cancer. Prostate $2: 89$

30. Watt KWK, Lee PJ, Timkulu TM, Chan WP, Loor R (1986) Human prostate-specific antigen: structural and functional similarity with serine proteases. Proc Natl Acad Sci USA 83:3166

31. Yam LT, Winkler CF, Janckila AJ, Li CY, Lam KW (1983) Prostatic cancer presenting as metastatic adenocarcinoma of undetermined origin. Cancer 51:283

M. P. W. Gallee, MD

Netherlands Cancer Institute

Department of Pathology

Plesmanlaan 121

1066 CX Amsterdam

The Netherlands 